\title{
Emergency College Library Facilities
}

Mr. Newcomb is librarian Associated Colleges of Upper New York.

THE FOLLOWING is an account of the I library program of The Associated Colleges of Upper New York through the first two years of its existence. Since these colleges have been and are by intent emergency and temporary, a general statement of what library facilities have been provided, how, and why, may be of some interest.

First a word about the institution itself. Three separate campuses have been operated since the fall of 1946 by the corporate entity, the Associated Colleges of Upper New York, hereafter called ACUNY. Champlain College is located in the former military barracks at Plattsburg, N.Y. and has had a peak enrolment of 1800 students. Mohawk College, closed in June I948, occupied the former Rhodes General Hospital at Utica, N.Y. and has enroled 2200 students. Sampson College occupies a portion of the Sampson Naval Base near Geneva, N.Y. It has had a maximum enrolment of 4500 students. ${ }^{1}$ ACUNY was incorporated in 1946 to provide emergency educational facilities at the college level for those qualified students who could not gain admission to existing colleges and universities because of lack of room. It was and is a private institution though its creation was urged by the New York state government and it has always been closely

${ }^{1}$ A fourth school, the Middletown Collegiate Center at Middletown, N.Y., has also been a part of ACUNY since 1947. It is essentially a community college operating within the facilities of the local high school with a comparatively small enrolment. Its nature and its problems have been quite different from the other three and for that reason it has not been considered in this article. allied with the New York State Department of Education. Its board of directors consists of $2 \mathrm{I}$ college and university presidents and other key figures in the educational pattern of the state.

It has offered the first two years of college work only, with students transferring to other institutions to complete their work and receive their degrees. Curricula are offered in liberal arts, business administration, and pre-engineering. Course offerings are the same on each campus and over-all department heads have been responsible to assure uniformity. The plan of uniformity between the three campuses has simplified the problem of the librarian in that three similar libraries have been required.

The writer was appointed librarian Sept. I, 1946. In a brief interview with President Asa S. Knowles, he was instructed "to set up three college libraries." $\mathrm{He}$ was somewhat taken aback by the generality of these words but soon came to recognize in them a fountainhead of answers to problems. At this time also he learned that Champlain would open September 19, and Sampson and Mohawk in the following month. None of the camp libraries remained, except that at Sampson there was enough library furniture for all three libraries.

\section{Objectives}

The first thing was to decide what the library program hoped to do. Obviously our first obligation was to the classroom, which meant providing the library materials necessary to support the instructional program. 
More education goes on in a college than was ever dreamed of in a classroom, and some of it goes on in the library. Our second objective, therefore, was to provide a core collection of books covering all fields of knowledge with which college freshmen and sophomores might reasonably be expected to be familiar, e.g. the classics and pseudo-classics, authoritative and standard works, basic reference tools, etc.

All our students would eventually complete their work in other institutions. Without some exposure to "standard" library organization and practice they would be at an added disadvantage. Therefore we decided to organize the libraries along traditional lines to the end that students skilled in the use of any ACUNY library would be able to use the library of the institution to which they transferred.

Each college would represent an additional two thousand or more persons to the community in which it was located. It would be unfair and inadequate to expect the libraries of these communities to provide all the recreational reading required by our students and faculty. We therefore agreed to furnish recreational reading material for the college community.

Since many of our faculty were recently discharged from the armed services and some were inexperienced in college teaching, our fifth objective was to provide those materials necessary for the faculty to keep informed and to refresh themselves in their fields of interest.

Such were the initial objectives. Probably no one would seriously quarrel with them and probably no two librarians would interpret them alike. In any event they were sufficient guides and we have not since had reason to change them materially.

\section{Organization and Staff}

Next to command attention was organization and staff. A number of factors recommended a central cataloging and acquisitions office, and such was established at Champlain. Its personnel has included a head of cataloging and acquisitions, an assistant cataloger and an assistant acquisitions librarian, together with supporting clerical and student help. It has been the job of this office to order and catalog material for the three colleges. The books themselves, however, have been sent directly from the vendor to the individual libraries and there have been made immediately available for use by going into an unclassified section of the open stacks.

Each library has had a "technical processes section" headed by a clerical worker with clerical and student assistants. This section has been responsible for receiving and reporting materials to the central office, for immediately processing materials for use as unclassified, for subsequently reprocessing when classification and cards came from Champlain, and for filing catalog and shelflist cards.

It was originally intended that this section would function with but general supervision by the resident head librarian. It has been found necessary, however, at each college to put a professional assistant in detailed charge of the section and this work has occupied from one-half to twothirds of her time. This modification was made necessary by turnover of student and clerical personnel and by a greater number of books unique to each campus than was originally foreseen. Another factor was the initial underestimate of the number of catalogers needed in the central office. This made it impossible for the head cataloger to visit each campus as frequently as would have been necessary were the technical processes section to have functioned without detailed supervision from a local professional.

The operation of each library has been under the direction of a resident head 
librarian assisted by two or three professional assistants, depending upon the campus, together with sufficient clerical and student help to relieve the staff of routine tasks. Traditional professional functional designations such as reference, circulation and reserve were not initially established, though there has been a tendency on each campus for the staff to divide work responsibility along these lines and at Sampson the position of reference librarian was established in 1947.

In all there have been I4 professional positions. Most staff members were contacted through the placement services of the A.L.A. and the Special Libraries Association. A complete staff was not assembled at any one time until the summer of 1947 , although each library had at least its resident head and one assistant by the time school began.

\section{Book Collections}

Having an idea of what we proposed to do and how we proposed to do it, the next thing was the acquisition of materials. What and how many?

Purely for administrative purposes it was estimated that 8000 volumes each at Champlain and Mohawk and I0,000 at Sampson would be needed to carry through the first year program which was to be primarily at the freshman level. There was no particular science or logic in this estimate. It seemed attainable and it seemed to be enough to provide at least minimum essential service. No estimate was made of the amount of additional materials required in the second year when both the freshman and sophomore programs would be in operation. Actually by the end of the second year Mohawk had approximately 13,000 volumes, Champlain 15,000 and Sampson i6,000.

In determining what we should get, it has been the policy to rely primarily on the recommendations of department heads and members of the library staff and only incidently to use standard lists and bibliographies. We could justify the purchase of only those materials for which there was an immediate or discernible need. The department heads could tell us what they planned to assign and what they would probably need to support the areas covered by their courses. The library staff from its daily contact with students and faculty and from its own experience could anticipate many needs and would quickly discover the more pressing weaknesses of the collections. Of course both groups used standard lists and bibliographies in making their recommendations.

The bulk of the collections has been purchased, but two other sources of material should be mentioned. These are the Traveling Libraries Section of the New York State Library at Albany and the duplicate collections of a number of colleges and universities in the state. These two sources were of particular importance in the early months of our existence since material from them could be secured quickly and with a minimum of paper work.

The State Library very generously offered to waive its normal lending procedures to permit us to make unlimited selection from their Traveling Libraries Section and to keep the books for an indefinite period. Various members of the library staff each spent a day or more in the stacks of the Traveling Libraries Section picking out titles which in their judgment would be useful. Also a few lists were checked by the state library staff. Whenever possible three copies of a title were taken, one copy being sent to each of the three colleges. In all, some 6000 books were borrowed from this source and a great many of these subsequently appeared as recommendations from department heads.

In October 1946, President Knowles 
wrote the college presidents on his board of directors requesting that we be given access to their library duplicates with a view to making selections of needed materials. In the course of the next month or so most of these colleges and universities were visited. As with the state library, selection was made on the basis of the librarian's judgment and recollection and the great value of the material was its immediate availability with a minimum of paper work. Most of this material was given outright, though a nominal price was paid in some instances. Approximately 4000 volumes were acquired from this source.

Subscriptions were placed for 218 periodicals and newspapers for each campus. Back files of approximately 50 periodicals from 1936 to date were collected for each library. The purpose in acquiring the back files of periodicals was to afford at least minimal resources through the use of which students could acquire the skills necessary for elementary term-paper level research. These periodicals proved to be one of our most difficult acquisitions and in this area the state library and the duplicate collections proved of inestimable value.

It was our initial intent that the three libraries would duplicate each other. It soon became apparent, however, that this was totally impractical with state library books and "gift". books and even with purchased materials. To have adhered to the initial plan would have made it necessary to refuse desirable additions simply because the same title could not be procured for one or both of the other colleges.

About two-thirds of the way through the most intensive phase of the acquisitions program, a study was made to determine the extent of uniformity among the three book collections. At that time there was a 47 per cent chance that any title found in one would be found in the other two collections, and a 57 per cent chance that a title in one would be in one of the other two. Of purchased material, which is perhaps of greater significance since it represents acquisition to fill a definite need, there was a 74 per cent chance that a title found in one would be in all three collections and an 89 per cent chance that it would be found in one of the other collections. An appreciable amount of purchased material was out-of-print or but-of-stock and had to be acquired through second-hand book channels.

\section{Use}

Use of the libraries has been gratifying from the beginning. At Sampson, for instance, the librarian arrived about a day before the students were supposed to begin reporting. Possibly 800 books had arrived from publishers and dealers but they were still in cartons. After starting the wheels going to get such things as shelves, tables, chairs and help, the librarian began unpacking some of the books. It was not long before he found he had a number of volunteers who were unpacking cartons ahead of him and rummaging behind him. It seemed undesirable and totally futile to attempt to stop these volunteers, and so the librarian took his stand near the door, stamp pad in hand, and as each volunteer left with his "find" it was duly stamped with ownership and a temporary record made of the charge. In such fashion approximately half the total book stock was circulated the first day.

By March 1947 the libraries had become sufficiently important in the History Department's work to warrant a request from its head that all incoming students be given instruction in use of the library. Although the request came about two months before the librarian felt the library facilities would be sufficiently well organized to warrant it, a program was begun and has been continued to date. 
Total circulation for the first academic year with a maximum book stock of 30,000 volumes was approximately 84,000 , of which 38,000 was nonreserve. Maximum enrolment for any length of time during this period was 4500 .

Figures for the second year are perhaps more significant in that they represent one phase of the productivity of a fairly well organized though still rapidly expanding collection. Also the second year reflects the full curricula offerings to both freshmen and sophomores. For this period total circulation was approximately 300,000 , of which 82,000 was nonreserve (two-week period) and 218,000 was reserve (one hour and overnight). During the second year the maximum book stock was approximately 44,000 and the top enrolment 8500 .

It is perhaps significant that the relatively small book collections, I3,000-16,000 volumes per campus, did sustain the gross use reflected in the foregoing. These figures compare favorably with institutions having many times the book stock available to our students. This experience would seem to confirm to some extent the belief held by many librarians that great numbers of books are not required to fulfill the needs of any present undergraduate academic program. Indeed, the writer feels that the relatively small but highly select book collections available to ACUNY students facilitated their use.

\section{What of the Future?}

The writer is frequently asked about the future disposition of these libraries. At this time he does not know. When Mohawk was closed, its library was consolidated with the Champlain and Sampson collections. Sampson closed in June and plans are now under way to consolidate its collection with the Champlain library. At this time it appears altogether possible that some sort of educational institution will remain permanently at Champlain. Presumably the present library will be inherited by whatever agency directs the permanent establishment.

Champlain is scheduled for operation again next year under its present organization. For at least that far ahead its main library problem will be the intelligent use of the considerable number of duplicate titles it will have.

\section{Interlibrary Loans from the College Viewpoint}

\section{(Continued from page 439)}

will be surprised to find out how many important scholarly titles they hold among themselves and that they can stand on their own feet instead of being beggars. This will encourage interlibrary loans on a much larger scale. I hope all of us will eventually rival with Sarah Lawrence's 950 books lent and borrowed per year.

\section{Another Farmington Plan}

Beyond the closer cooperation in interlibrary loans, I foresee in the more distant future some kind of a Farmington plan for college libraries. That is, college libraries of a given area will agree which subjects they wish to develop more strongly, leaving the special care of others to their neighbors. By the system of free interchange they will be just as able to have these books available to their own clientele, when needed, as if they had acquired them themselves. This will bring about a much more reasonable and effective use of our book budgets. I hope I will still live to see the day when the last trace of institutional isolationism disappears from our college libraries. 